\title{
The antecedents of cross-functional coordination and their implications for marketing
}

\section{adaptiveness}

\begin{abstract}
As the gap between accelerating rate of change and organizational capability in responding to it widens, managers face increasing challenges to coordinate and align diverse intra-firm functions. Although coordination across functions in an organization is necessary for integrating complex resources such as responding to uncertainty in business environments, little is known about the internal conditions of a firm in which cross-functional coordination influences marketing adaptiveness. Marketing adaptiveness recognizes the potential conflicting goals of intra-firm functions, and the need to identify disparate but interdependent organizational resources to fit the external environment. In order to account for the potential interactions of multiple conditions in cross-functional coordination, we use fuzzy-set qualitative comparative analysis to analyze survey data of 274 managers in Egyptian firms operating in uncertain environments based on the motivation-ability-opportunity framework and configuration theory. The findings show that the causal pathways leading to cross-functional coordination and marketing adaptiveness can be enhanced by resource dependency, cross-functional teams, multifunctional training, and management support. In particular, management support is a crucial condition for coordination in support of cross-functional teams and multifunctional training. While resource dependency is an important internal factor for coordination, a high resource dependency can result in a negative effect on marketing adaptiveness.
\end{abstract}

Keywords: Motivation-ability-opportunity framework, Cross-functional coordination, Marketing adaptiveness, Configuration theory, Fuzzy-set comparative qualitative analysis (fsQCA). 


\section{Introduction}

Businesses operating in highly uncertain business environments are characterized by short product life cycles, fast changing technologies, rapid changes in the marketplace and uncertain economic and political situations. Such conditions require firms to develop effective cross-functional coordination (CFC) among interdependent functions in an organization particularly in enhancing marketing adaptiveness. From a capability perspective, dynamic capabilities imply marketing adaptiveness in terms of the ability of a firm to change its resource allocation and operational routines to match the changing environment (Vakratsas and Ma, 2009). While functional specialization generates certain benefits, an organization with silos hinders the cross-functional dialogue needed to create adaptive capabilities (Day, 2011). Marketing adaptiveness recognizes the importance of communications and flexibility in intra-firm coordination to identify necessary resources and match environmental demands and opportunities such as in the context of personal selling (Weitz et al., 1986) and adaptive decision-making (Bauer et al., 2013). New product development studies highlight the importance of cross-functional coordination for new product success (Ernst et al., 2010, Kuen-Hung et al., 2013, Lee and Wong, 2012, Troy et al., 2008). The development of successful market-oriented firms relies on inter-functional coordination as a key component that is critical to market responsiveness and marketing performance (Kohli and Jaworski, 1990, Narver and Slater, 1990, Slater and Narver, 1995). Thus, marketing adaptiveness can be influenced by the conditions supporting a firm's cross-functional coordination to respond to uncontrollable external environments and to consolidate its internal environment to fit within and adapt to the external environment (De Luca and Atuahene-Gima, 2007, Tsai and Hsu, 2014).

Despite the benefits of efficient cross-functional coordination in terms of improved ability to handle complexity and enhanced responsiveness (Holland et al., 2000), cross-functional coordination can encounter obstacles simultaneously from different functions such as conflicting organizational goals and lack of cooperation (Wall and Lepsinger, 1994). In this instance, crossfunctional coordination can be both difficult and inefficient (Galbraith, 1994, Kahn and Mentzer, 
1998), which may negatively impact on efficient decision-making, and increase new product development failures and conflict over resources (Cuijpers et al., 2011, Troy et al., 2008). For example, the rapid flow of information from various functional units may affect the ability of firms to make decisions, process information and prioritize tasks (Eppler and Mengis, 2004, Klingberg, 2009). Prior research has advanced different integrating mechanisms to enhance cross-functional coordination; these range from redesigning compensation systems to changing workplace architecture (see Griffin and Hauser 1996 for a review). Although some studies empirically examine and provide useful insights into the efforts to improve cross-functional relations (e.g., Griffin and Hauser, 1996, Pinto et al., 1993), the conditions influencing the efforts of cross-functional coordination are under-explored particularly for firms operating in uncertain business environments. As such, research about the conditions in which firms enhance cross-functional coordination can help managers to better coordinate resources across functions and respond in a timely fashion to changes (De Luca and Atuahene-Gima, 2007, Tsai and Hsu, 2014).

The present study draws on the motivation-ability-opportunity (MAO) framework (Maclnnis et al., 1991) as an encompassing framework to capture the relative effectiveness of the various crossfunctional mechanisms in terms of a firm's motivation, ability and opportunity to enhance crossfunctional coordination and marketing adaptiveness. First, the focus on motivation recognizes the importance of enlisting support throughout the organization from leadership, interdependency and reward systems (Olson et al., 1995). Second, the ability of different functional units to coordinate reflects optimal integration and use of a firm's resources, skills and capabilities across functions (Tsai and Hsu, 2014). Third, the MAO framework examines the opportunity for cross-functional coordination such as in new product development and new challenges of operating in uncertain business environments (Ruekert and Walker, 1987a).

Specifically, the focus is not only on the effectiveness of cross-functional coordination but also on the adaptiveness of firm-level marketing performance outcomes. We propose that crossfunctional coordination is not driven by a single factor, but rather by a configuration of causal 
factors. Previous studies tend to examine only one or two factors that support cross-functional coordination (Maltz and Kohli, 2000). This not only gives an incomplete picture of the conditions that support cross-functional coordination but also overlooks the relative and joint effects of the various cross-functional mechanisms. We draw on configuration theory which posits that a set of the same variables can impact on an outcome in various ways depending on how these variables are combined (Ordanini et al., 2014). There are three main principles in configuration theory: first, there is no single factor that can lead to an outcome of interest.; second, causal factors do not operate in isolation; and third, the same causal factor can have different impacts on the outcome depending on the context (Greckhamer et al., 2008). Ragin (2000) explains this as the concept of "equifinality" which argues that the same outcome can be achieved by different configurations of the causal factors.

We approach our investigation by using fuzzy-set qualitative comparative analysis (fsQCA) which is considered appropriate for complex configuration analysis (Fiss, 2007; Ragin, 2000). FsQCA is an analysis of set memberships and employs Boolean algebra to identify configurations for the necessary and sufficient conditions required for an outcome. Our study's findings confirm that individual coordination drivers have complex trade-off effects on cross-functional coordination and marketing adaptiveness. Results show that different combinations of mechanisms offer sufficient conditions for the desired outcomes. These findings demonstrate that fsQCA provides a deeper understanding about cross-functional coordination and marketing adaptiveness than the conventional techniques such as regression analysis do.

Our research context is Egypt as it represents a highly uncertain and volatile business environment. Prior research suggests that in such an environment, marketing adaptiveness can play a pivotal role in helping firms attain and sustain competitive advantages, whereas the absence of such capabilities will render superiority and advantages short-lived (Rindova and Kotha, 2001, Woiceshyn and Daellenbach, 2005, Zollo and Winter, 2002, Zott, 2003). The context of Egypt provides an opportunity to test theories related to intra-firm relationships and marketing 
adaptiveness outside the USA and European countries. This may validate the generality of prior research findings conducted in developed countries by testing them in a developing country context. There is a lack of empirical research addressing effective mechanisms to enhance intra-firm crossfunctional coordination and marketing adaptiveness in developing economies. Since Egypt is a promising major economy in the Middle East and North Africa (MENA) region, the present study can benefit firms operating in dynamic and uncertain markets by providing a holistic understanding of causal pathways of different conditions necessary for cross-functional coordination in enhancing marketing adaptiveness.

The remainder of this article is organized as follows. The next section focusses on the conceptual model and the development research propositions of the study. The third section describes the methodology of this study. This includes research design, data collection and constructs measurement. This is followed by detailed descriptions and interpretations of the data analysis using fuzzy-set qualitative comparative analysis. The article concludes with the discussion and conclusion section which includes implications for theory, practice and research.

\section{Conceptual model and research propositions}

\subsection{Conceptual model}

The interest in cross-functional coordination has long been an underlying focus of the market orientation construct. Market orientation stresses the importance of inter-functional coordination, and that employees at all levels in every functional unit need to be committed to information gathering and dissemination, and responsiveness to changing business environments (Kohli and Jaworski, 1990; Narver and Slater, 1990; Slater and Narver, 1994). Uncertain and dynamic environments disrupt the ability of specialized functional units in responding to changes, and both conditions necessitate coordination across functional units (Galbraith, 1973). This study focusses on intra-firm coordination - that is, coordination among employees and across functional units within a firm (Mintzberg et al., 1996), which affects a firm's capability to share customer and competitor information for strategic integration of all functions in the process of creating customer value 
(Narver and Slater, 1990, Song et al., 1997). The ability to coordinate across functions not only allows firms to swiftly respond to environmental changes (Neill et al., 2007) but also to gain access to a wider range of tacit knowledge dispersed across the organization to build valuable collective knowledge (Arnett and Wittmann, 2014, Atuahene-Gima, 2005, Hirunyawipada et al., 2010). A firm's knowledge of how to support and enhance cross-functional coordination can be a competitive strategy to enable firms to utilize and deploy dispersed resources and improve performance (Eisenhardt and Martin, 2000, Hult et al., 2005, Kohli and Jaworski, 1990, Narver and Slater, 1990).

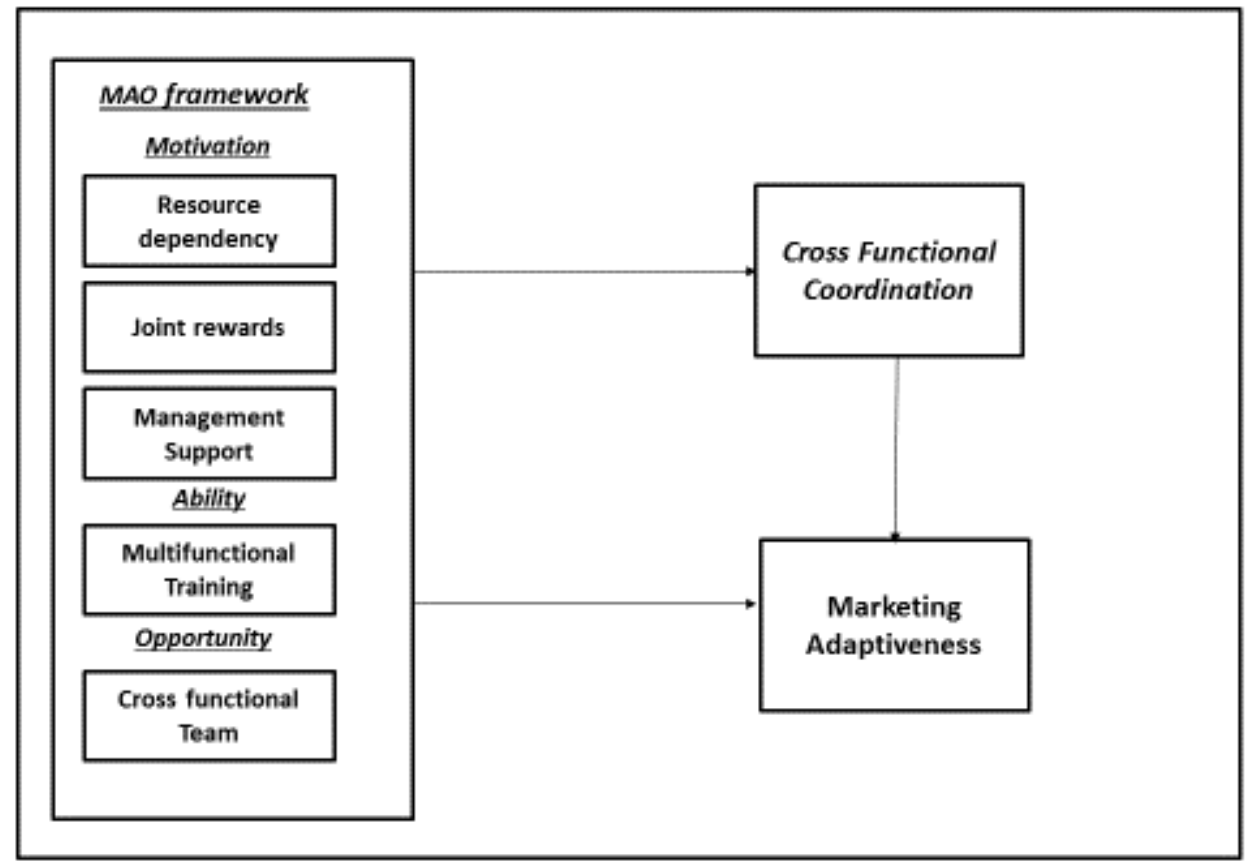

Figure 1: The research conceptual model

Figure 1 provides an overview of the conceptual framework of this study. The antecedents of CFC have been developed from the motivation-ability-opportunity (MAO) framework, which can be examined to create the conditions and behaviors for supporting and enhancing cross-functional coordination. The MAO framework was originally applied to information processing and advertising effectiveness (Maclnnis et al., 1991) and it has been examined in different literature streams such as social marketing, organization information processing, human resource management, information systems research, and innovation (e.g., Clark et al., 2005, Siemsen et al., 2008, Tang et al., 2014). This framework is based upon basic concepts of psychology, in that 
motivating certain behaviors is influenced by ability in terms of skills and capabilities requisite for the performance of the behaviors, and opportunity is concerned with the conditions facilitating the performance of the behaviors (Maclnnis et al., 1991). As an encompassing framework, MAO has the potential to support cross-functional coordination and enhance marketing performance.

The motivation dimension of the MAO framework includes resource dependency, joint rewards and management support. Resource dependency theory recognizes that environmental and marketplace uncertainties necessitate the coordination of different functional units to utilize their knowledge and skills to resolve these uncertainties (Pfeffer and Salancik, 1978). Previous studies suggest a positive relationship between resource dependency and coordination within a firm (Calantone and Rubera, 2012, Olson et al., 1995). Gupta et al. (1986) argue that organizational units which are highly dependent upon each other's resources are likely to increase the use of coordination mechanisms. In addition, previous studies have shown that high resource interdependency can lead to more interactions between marketing and other functions (Olson et al., 1995, Ruekert and Walker, 1987b, Song and Swink, 2009).

Joint rewards systems, both financial and non-financial, associated with certain kind of behaviors and attitudes can send a powerful message to motivate employees of an organization (Beer et al., 1988). Good and Schultz (1997) argue that evaluation and reward systems are mechanisms that a firm can use to stimulate and foster cooperation between functional areas by bringing together disparate individuals to achieve common goals. Numerous studies have shown that joint reward systems have a positive effect on coordination and integration of marketing with other functional units (Arndt et al., 2011, Hutt, 1995). Joint rewards encourage employees to aim for broad crossfunctional goals which help employees to identify with their organization and collaborate with other functional units. In a recent article, by using agent based models, Ladley et al. (2015) demonstrated the value of using joint reward systems on work group behavior and performance under different task conditions. They concluded that the use of group-based systems produces more cooperative behavior. 
Management support has been regarded by control theory (Ayers et al., 1997) as a process of formalizing control mechanisms through allocation of resources and activities. For example, the extent to which management provides resources and delegates authority can encourage cooperative behaviors to support cross-functional coordination (Song et al., 1997). Prior research has shown that management support has a positive influence on coordination across functional units and organization performance (Chimhanzi and Morgan, 2005, Gupta and Wilemon, 1991, Kuen-Hung et al., 2013, Le Meunier-FitzHugh et al., 2011). In addition, management support has been shown to promote cross-functional integration by providing the necessary resources and valuing cooperation (Gupta et al., 1986).

The ability dimension of the MAO framework is assessed by multifunctional training in terms of an employee's skills and proficiencies to engage in cross-functional coordination. It has long been noted that differences in employees' educational backgrounds and training are the grounds for miscommunication in organizations (Kahn and Mentzer, 1998, Lawrence and Lorsch, 1967). Multifunctional training focusses on developing employees with certain types of skills and capabilities in order to facilitate coordination with different functional units. For example, employees can better understand other functions' terminologies which can help reduce language barriers between functions (Griffin and Hauser, 1996). Prior research has shown that multifunctional training can help managers to better appreciate goals and perspectives, and recognize priorities and perspectives of other functional units such as in new product development (Griffin and Hauser, 1996, Gupta et al., 1986, Moenaert and Souder, 1990) and market orientation (e.g., Jaworski and Kohli, 1993, Ruekert, 1992).

The opportunity dimension of the MAO framework consists of cross-functional teams. A crossfunctional team can be defined as a collection of individuals from different functional units who have a common purpose of enhancing performance goals (Maltz et al., 2001). It can be a purposeful task force to achieve broad objectives, and tackle organizational threats and opportunities (Griffin 
and Hauser, 1996, Pinto et al., 1993). Past studies show that a cross-functional team is a main contributor to improved market success, profit generation, and reduced development cycle time (Atuahene-Gima, 1996, Brown and Eisenhardt, 1995, Enz and Lambert, 2012, Nakata and Im, 2010). Teamwork across functions facilitates the integration of diverse skills within an organization and many organizations regard it as an effective way to deal with environmental complexity (Griffin and Hauser, 1996; Pinto et al., 1993).

Although the positive effects of cross-functional coordination may lead to improved marketing performance, it is important to examine and capture relevant marketing performance outcomes. For example, it has been noted that cross-functional coordination may be inefficient (Song and Xie, 2000), ineffective and costly in the use of coordination mechanisms (Jansen et al., 2009), and inflexible as in conflicts among different functional units (Parry and Song, 1993). We examine the effect of cross-functional coordination and its driving mechanisms on marketing adaptiveness. Marketing adaptiveness focusses on the ability of the organization to respond to environmental changes (Ruekert et al., 1985). This measure is consistent with Day's (2011) article on 'closing the marketing capabilities gap', whereby cross-functional coordination can support firms to create adaptive capabilities for swift response to environmental changes. In this sense, marketing adaptiveness can be defined as the firm's ability to identify and capitalize on emerging marketing opportunities (Wang and Ahmed, 2007) and can be manifest in a firm's strategic flexibility in resource deployment (Sanchez, 1995) or its ability to align internal resources with external demand.

\subsection{Research propositions}

Based on the literature reviewed in the previous section, we argue that cross-functional coordination is a complex phenomenon. Previous research has shown contradictory results on the effectiveness of coordination mechanisms and whether cross-functional coordination fosters or inhibits performance. Furthermore, given the limited resources of firms, a strategic choice is usually made on specific mechanisms to be adopted to enhance coordination between different functional units. Since, to date, there is no magic recipe to achieve the desired coordination behavior, we investigate 
which configuration of popular mechanisms is more important in achieving cross-functional coordination - which might also lead to adaptive marketing. We posit that the causal factors identified in the conceptual model will enhance or inhibit coordination, depending on how they are configured with other factors.

A growing number of studies in marketing and management literature advocate the use fsQCA to analyze configurations (e.g., Fiss, 2011, Ganter and Hecker, 2014, Leischnig and Kasper-Brauer, 2015, Meuer, 2014, Ordanini et al., 2014, Skarmeas et al., 2014, Woodside et al., 2011, Woodside et al., 2015, Wu et al., 2014). While the configurations of factors affecting an outcome can potentially be numerous, equifinal configurations that effectively explain the outcome normally reduce to a few logical combinations of variables (Ordanini et al., 2014, Ragin, 2008). Thus, the purpose of configuration analysis is to discover those few equifinal configurations for the desired outcomes of our research (cross-functional coordination and marketing adaptiveness).Our research propositions are:

Proposition 1: Disparate configurations of causal factors are equifinal in leading to cross-functional coordination

Proposition 2: The same factors can either foster or inhibit cross-functional coordination, depending on how it is configured with other causal factors.

Proposition 3: A configuration of cross-functional coordination with other organizational factors will lead to marketing adaptiveness.

\section{Methodology}

\subsection{Data collections}

The research is conducted in Egypt targeting middle-size to large firms. A preliminary qualitative study was conducted before the administration of the research questionnaire to confirm the applicability of the research conceptual model in the Egyptian culture (Miles and Huberman, 1994). Semi-structured interviews with 12 managers from different functional units in seven Egyptian firms were conducted. The interviews revealed that, as suggested in Western literature, cross- 
functional coordination is a vital issue for firms' performance, but it is usually too complicated for organizations to apply it. In order to test the research hypotheses a questionnaire was developed targeting mid-level managers of different functional units inside middle-size to large firms operating in Egypt. The questionnaire was pre-tested for clarity and appropriateness through interviews with four mid-level managers.

Data were collected using surveys (Arabic and English). A standard email was sent to email addresses for the 1,470 firms listed in the American Chamber of Commerce and to more than 10000 email addresses of Egyptian firms included in an email business directory. This method which is generally used in research conducted in developed countries resulted in a low response rate (1.4\%) despite the use of a few rounds of reminders. The low response rate provided evidence that this method which is the predominant method used in Western literature is, to a large extent, not recommended to be used in the Egyptian context. Therefore, to increase the number of responses, the researcher personally visited some companies to request their participation in the survey which proved to be more effective in the Egyptian context. Data collection resulted in a dataset containing 274 questionnaires from 52 firms: 27 (52\%) of these firms are manufacturing firms and 25 (48\%) are service firms. Most of the firms are local firms (63\%) and the rest are multinational firms (37\%): and $93 \%$ of the respondents preferred to fill the English surveys. The firms' age ranged from eight years to 140 years, and participating managers have been working in their companies between two and 20 years. While $60 \%$ of the participating managers are males, $40 \%$ are female, and the average age is 40 years old.

\subsection{Construct measurement}

The research used existing validated scales adapted from prior research with minor modifications based on feedback from the pilot study. Due to the application of the constructs in a different cultural context, the reliability and validity of the constructs generated some divergent results. In order to purify the measures to be used in further analysis, several techniques were used. First, reliability analysis and exploratory factor analysis were computed. This resulted in the deletion of 
items when cross-loadings or weak loadings were identified even if the construct ended with one item as this is not expected to reduce the construct' predictive validity (Bergkvist and Rossiter, 2007). Reliability is estimated via internal consistency and Cronbach's alpha, and validity is estimated with factor analysis and inter-correlation between constructs. Principal components analysis with Varimax rotation was deemed appropriate. Factors were retained only if they possessed an Eigenvalue greater than one, accounted for over $50 \%$ of variance, and if they were conceptually clear and interpretable (Churchill, 1979). Further analysis for reliability and validity was assessed with confirmatory factor analysis. The final items used in testing the research propositions, means, standard deviation, and reliability results are reported in Appendix 1.

Table 1: Correlation matrix

\begin{tabular}{|c|c|c|c|c|c|c|c|c|c|}
\hline Constructs & Mean & $S D$ & 1 & 2 & 3 & 4 & 5 & 6 & 7 \\
\hline 1. Adaptiveness & 4.68 & 1.66 & 1 & & & & & & \\
\hline $\begin{array}{l}\text { 2. Cross-functional } \\
\text { coordination }\end{array}$ & 5.1 & 1.1 & $1.79 * *$ & 1 & & & & & \\
\hline 3. Resource Dependency & 5 & 1.68 &.-.008 & $.764 * *$ & 1 & & & & \\
\hline 4..Top management support & 6 & 0.41 & $.246 * *$ & $.200 * *$ & $.179 * *$ & 1 & & & \\
\hline 5. Joint Reward Systems & 5.7 & 0.79 & $.385^{* *}$ & $.319 * *$ & $.254 * *$ & $.294 * *$ & 1 & & \\
\hline 6. Multifunctional Training & 6.1 & 0.59 & $.193 * *$ & 0.59 & 0.005 & -0.022 & $.165 * *$ & 1 & \\
\hline 7.Cross-Functional Team & 5.8 & 0.59 & .016 & $.263 * *$ & $.239 * *$ & $.184 * *$ & $.285 * *$ & $.519 * *$ & 1 \\
\hline
\end{tabular}

Notes: $\boldsymbol{S D}$ : Standard Deviation, **Correlation is significant at the 0.01 level (2-tailed); *Correlation is significant at the 0.05 level (2tailed).

Table 1 illustrates the means, standard deviations, and correlations between constructs.

As shown in the table, none of the estimated correlation coefficients has an absolute value higher than 0.80 . This finding implies that the relationships between variables are generally asymmetric, and thus alternative combinations of causal conditions can lead to the same outcome (Woodside, 2013). As a consequence of these results, the present study examines the roles of the independent variables on cross-functional coordination and marketing adaptiveness using fsQCA.

\subsection{Common method bias}

As this research uses the self-reported survey, common method bias can be a potential problem and needs to be controlled. In designing our survey we assured participants' of anonymity and confidentiality in order to reduce their evaluation bias. Moreover, we collected data from different 
managers from the same firm to control for common method bias (Podsakoff and Organ, 1986).

Harman's one-factor test was conducted to test the presence of common method effect in the data. All the variables were subjected to an exploratory factor analysis, using principal component analysis with Varimax rotation. The factor analysis revealed the presence of seven distinct factors with Eigenvalue greater than 1.0, rather than a single factor. The seven factors combined accounted for $65 \%$ of the total variance; the first (largest) factor did not account for a majority of the variance $(20 \%)$. The results suggest that common method variance is not of great concern and thus is unlikely to confound the interpretations of findings (Podsakoff and Organ, 1986).

\section{Analytical approach}

\subsection{Fuzzy-set qualitative comparative analysis ( $f_{s} Q C A$ )}

We investigate our configuration framework using fuzzy-set qualitative comparative analysis (Fiss, 2007, Ragin, 2000). FsQCA is an analysis of set memberships and employs Boolean algebra to identify configurations for the necessary and sufficient conditions for an outcome. FsQCA differs from regression analysis and conventional statistical techniques as it allows researchers to go beyond the net effect analysis to acquire more insights about the configurational complexities of the relationships between antecedents and outcomes (Woodside, 2013). There are three main advantages of using fsQCA over regression analysis: first, fsQCA does not assume symmetry and thus the relationship between independent and dependent variables is asymmetric, and second, the concept of "equfinality" indicates that there are usually multiple pathways and solutions leading to a desired outcome. Finally, fsQCA enables researchers to understand the causal complexities of the combination of different variables in the outcome. Hence the focus is not on the estimation of the independent variables' net effect on the dependent variables, but on the estimation of the effect of combinations of causal factors on an outcome (Fiss, 2007).

\subsubsection{Data Calibration (transformation of construct measures)}

We performed our analysis using a free software program fs/QCA 2.5 (fsQCA.com). The first procedure in fsQCA is the development of the set membership measures "data calibration". Data cali- 
bration transforms the original measures to a score reflecting the degree of membership in the target set. As suggested by Ragin (2000), the researcher has to identify certain criteria for three breakpoints in the fuzzy-set calibration ( 1 for full membership, 0.50 for the crossover point, and 0 for full non-membership). We based the three qualitative anchors for the calibration - i.e., full membership threshold, full non-membership threshold, and the crossover point threshold - on the seven-point Likert scale (Ordanini et al., 2014). The seven-point Likert scale possesses the qualities of the fuzzy set in terms of having a floor (1), ceiling (7) and crossover point (mean or median) (Ordanini and Maglio, 2009). However, ordinal scales reflect measures of general phenomena, while fuzzy sets measure the degree to which a case is a member of a set. Therefore, the researcher has to specify the three breakpoints based on prior substantial knowledge, as the calibration process may bias interpretation of results. As there is no prior knowledge about these thresholds for our research constructs, we fixed the calibration of our measures on the end points and mid-points of the Likert scales in line with some studies applying set-theoretic analysis (e.g., Leischnig and Kasper-Brauer, 2015). The full membership threshold was fixed at the rating of 7, the full non-membership threshold was fixed at the rating of 1 ; and, the crossover point was fixed at 4.

\subsubsection{Construction and refinement of the truth table}

After generating the fuzzy-set measures for each construct, fsQCA applies Boolean algebra rules to build membership scores for all the possible configurations of predictors of an outcome which is called truth table (Ragin, 2008). The truth table consists of all the possible combination of the binary states that is, presence or absence, of the causal factors (i.e. $2^{\text {number of causal factors }}$ ) rows (Ragin, 2008). Each row in the table represents a different configuration of the causal factors, the number of cases with fuzzy-set membership scores greater than .5 , and the proportion of cases that are consistent with the outcome (consistency).

Then the truth table has to be refined and reduced based on two conditions: frequency and consistency. Frequency refers to the minimum number of cases that need to be considered for a solution (Ragin, 2008). In this study, frequency cut-off was set at 3 so that the low-frequency 
combinations were treated as logical remainders (Greckhamer et al., 2008). Consistency measures the proportion of consistent cases in which the causal sets are members of the outcome sets (Fiss, 2011; Ragin, 2008) and ranges from 0 to 1 . Configurations with high consistency scores indicate pathways that almost always lead to the given outcome condition (Ragin, 2008). FsQCA literature recommends a minimum consistency of 0.75 ; in our study we set the consistency cut-off at 0.80 as suggested by Ragin (2008). Table 2 shows the truth table for the distribution of configuration in our sample for cross-functional coordination as an outcome. Table 3 shows the truth table for the distribution of configuration in our sample for marketing adaptiveness as an outcome.

Table 2: Truth table for cross-functional coordination as an outcome*

\begin{tabular}{|ccrrrrrrr|}
\hline res & reward & sup & mft & cft & number & cfc & raw consist. \\
\hline 1 & 1 & 1 & 1 & 1 & 155 & 1 & 0.927 \\
0 & 1 & 1 & 1 & 1 & 66 & 0 & 0.570 \\
0 & 0 & 1 & 1 & 1 & 19 & 0 & 0.740 \\
1 & 0 & 1 & 1 & 1 & 16 & 1 & 0.841 \\
1 & 1 & 1 & 0 & 0 & 3 & 1 & 0.918 \\
0 & 1 & 1 & 0 & 1 & 3 & 1 & 0.880 \\
0 & 1 & 1 & 1 & 0 & 2 & 0 & 0.964 \\
0 & 1 & 1 & 0 & 0 & 2 & 0 & 0.883 \\
1 & 1 & 1 & 1 & 0 & 1 & 0 & 0.991 \\
1 & 0 & 1 & 1 & 0 & 1 & 0 & 0.993 \\
0 & 0 & 1 & 1 & 0 & 1 & 0 & 0.952 \\
\hline
\end{tabular}

Note: res=resource dependency; sup=management support; $\mathrm{mft}=$ multi-functional training; $\mathrm{cft}=\mathrm{cross}$ functional teams; reward = joint reward systems; $\mathrm{cfc}=$ cross-functional coordination. $*$ Bold $=$ sufficient configurations; italics $=$ necessary configurations .

Table 3: Truth table for marketing adaptiveness as an outcome*

\begin{tabular}{|c|c|c|c|c|c|c|c|c|}
\hline res & reward & sup & mft & cft & cfc & Number & adapt & raw consist. \\
\hline 1 & 1 & 1 & 1 & 1 & 1 & 140 & 0 & 0.777 \\
\hline 0 & 1 & 1 & 1 & 1 & 0 & 53 & 1 & 0.823 \\
\hline $\mathbf{0}$ & $\mathbf{0}$ & 1 & 1 & 1 & $\mathbf{0}$ & 16 & $\mathbf{0}$ & 0.770 \\
\hline 1 & 1 & 1 & 1 & 1 & $\mathbf{0}$ & 13 & $\mathbf{0}$ & 0.752 \\
\hline 0 & 1 & 1 & 1 & 1 & 1 & 9 & 1 & 0.892 \\
\hline 1 & $\mathbf{0}$ & $\mathbf{1}$ & 1 & 1 & $\mathbf{0}$ & 8 & $\mathbf{0}$ & 0.632 \\
\hline 1 & $\mathbf{0}$ & 1 & 1 & 1 & $\mathbf{1}$ & 7 & $\mathbf{0}$ & 0.716 \\
\hline 0 & 0 & 1 & 1 & 1 & 1 & 3 & 1 & 0.828 \\
\hline 1 & 1 & 1 & $\mathbf{0}$ & $\mathbf{0}$ & $\mathbf{0}$ & 2 & $\mathbf{0}$ & 0.916 \\
\hline $\mathbf{0}$ & 1 & 1 & $\mathbf{0}$ & 1 & $\mathbf{0}$ & 2 & $\mathbf{0}$ & 0.813 \\
\hline $\mathbf{0}$ & 1 & $\mathbf{1}$ & $\mathbf{0}$ & $\mathbf{0}$ & $\mathbf{0}$ & 2 & $\mathbf{0}$ & 0.762 \\
\hline 1 & 1 & 1 & 1 & 0 & 1 & 1 & $\mathbf{0}$ & 0.886 \\
\hline 1 & 1 & 1 & $\mathbf{0}$ & $\mathbf{0}$ & 1 & 1 & 0 & 0.864 \\
\hline 1 & 0 & 1 & 1 & 0 & 1 & 1 & 0 & 0.855 \\
\hline 0 & 1 & 1 & 1 & 0 & 1 & 1 & 0 & 0.892 \\
\hline 0 & 1 & 1 & 1 & 0 & 0 & 1 & 0 & 0.884 \\
\hline 0 & 1 & 1 & 0 & 1 & 1 & 1 & 0 & 0.889 \\
\hline 0 & 0 & 1 & 1 & 0 & 0 & 1 & 0 & 0.848 \\
\hline
\end{tabular}


Note: res=resource dependency; sup=management support; $\mathrm{mft}=$ multi-functional training; $\mathrm{cft}=\mathrm{cross}$-functional teams; reward = joint reward systems; $\mathrm{cfc}=$ cross-functional coordination; adapt $=$ marketing adaptiveness

*Bold $=$ sufficient configurations; italics $=$ necessary configurations.

\subsubsection{Analysis of configurations}

In the final procedure, fsQCA evaluates which configurations of variables can act as sufficient conditions for the outcome of interest. This requires cross-case analysis of memberships between the causal sets and the outcome sets. The fsQCA software package uses Quine-McCluskey algorithm to obtain the final solution. As explained by Ragin (2008), the algorithm conducts a counterfactual analysis of the causal conditions that lead to the outcome in question. It analyzes set relationships by first detecting combinations of causal conditions that consistently lead to an outcome and then removing the causal conditions that only occasionally bring about the outcome, thus indicating that these causal conditions are not essential elements of a sufficient configuration for the outcome (Ragin, 2008). The output of this analysis provides three types of solutions: complex, parsimonious, and intermediate. Each of these solutions derives a set of pathways (i.e., statements of complex causal conditions) that are predictive of a high membership score in the outcome condition (Ragin, 2008). The parsimonious solution uses the reminders - the combinations of causal factors not observed in the data set - to simplify the solution. Therefore, the parsimonious solution should only be used if the assumptions for using the remainders are fully justifiable. The intermediate solution differentiates between "easy" and "difficult" assumptions and takes into consideration only the "easy" remainders when simplifying the solution. The designation of "easy" versus "difficult" is based on user-supplied information regarding the connection between each causal condition and the outcome. Finally the complex solution makes no simplifying assumptions and is recommended to be used as the final solution when there is no basis for simplifying the solution (Ragin and Sonnett, 2005).

The final analysis reports information on two important measures in fsQCA: consistency and coverage. Coverage measures how much of the outcome is explained by each solution term and the solution as a whole, and they have a similar meaning to that of magnitude effects (R2) in regression 
analyses (Woodside, 2013). Table 4 shows the results of the complex configurational analysis for cross-functional coordination and marketing adaptiveness.

Table 4: Sufficient configurations for cross-functional coordination and marketing adaptiveness

\begin{tabular}{|c|c|c|c|c|c|}
\hline Configurations & Consistency & $\begin{array}{c}\text { Raw } \\
\text { coverage }\end{array}$ & $\begin{array}{l}\text { Unique } \\
\text { coverage }\end{array}$ & $\begin{array}{l}\text { Solution } \\
\text { coverage }\end{array}$ & $\begin{array}{c}\text { Solution } \\
\text { consistency }\end{array}$ \\
\hline \multicolumn{6}{|c|}{$\begin{array}{l}\text { Configuration solutions for cross-functional coor- } \\
\text { dination }\end{array}$} \\
\hline 1. res*sup*mft*cft & 0.89 & 0.79 & 0.75 & 0.81 & 0.88 \\
\hline 2. res*reward*sup* ${ }^{*} \sim \mathrm{mft} * \sim \mathrm{cft}$ & 0.92 & 0.053 & 0.007 & & \\
\hline 3. $\sim$ res*reward*sup* $\sim \mathrm{mft} * \mathrm{cft}$ & 0.88 & 0.047 & 0.009 & & \\
\hline \multicolumn{6}{|c|}{ Configuration solutions for marketing adaptiveness } \\
\hline 1. res*reward*sup*mft*cft & 0.77 & 0.33 & 0.11 & 0.34 & 0.76 \\
\hline 2. res*sup* $\mathrm{mft}^{*} \mathrm{cft}^{*} \mathrm{cfc}$ & 0.85 & 0.23 & 0.01 & & \\
\hline
\end{tabular}

Note: res=resource dependency, sup=management support; $\mathrm{mft}=$ multi- functional training; cft=cross-functional teams; reward $=$ joint reward systems, $\mathrm{cfc}=$ cross-functional coordination; $\sim=$ absence of a condition.

Table 4 summarizes the results obtained from the fsQCA analysis. The results show three configurations of causal conditions explaining cross-functional coordination, and two configurations explaining marketing adaptiveness. Coverage and consistency scores for each solution are reported as well as for the overall solutions. FsQCA distinguishes between raw coverage and unique coverage for each solution. Raw coverage measures the proportion of memberships in the outcome explained by each term of the solution, and unique coverage measures the proportion of memberships in the outcome explained solely by each individual solution term, excluding memberships that are covered by other solution terms (Ragin, 2000). Research (e.g., Ragin, 2008; Woodside, 2013) suggests that a model (solution) is informative when consistency is above 0.75 and coverage is above 0.25 .

Analysis showed three configurations (pathways) leading to cross-functional coordination with an overall solution coverage of .81 and a consistency of .88 , which indicates that a substantial proportion of the outcome is covered by the three configurations. Configuration 1 (raw coverage=.79, unique coverage $=.75$, consistency $=.89$ ) indicates a combination of resource dependency, management support, multifunctional training, and cross-functional teams. Configuration 2 (raw coverage $=$ .053 , unique coverage $=.007$, consistency $=.92$ ) combines the presence of resource dependency, joint reward systems and management support with the absence of multifunctional training and 
cross-functional teams. In this configuration, joint reward systems seem to play a significant role in compensating for the absence of multifunctional training and cross-functional teams. Configuration 3 (raw coverage $=.0 .047$, unique coverage $=.009$, consistency $=.88)$ describes a combination of the presence of joint reward systems, management support and cross-functional teams and the absence of resource dependency and multifunctional training.

The configuration solutions for marketing adaptiveness indicate two solutions statements with overall solution coverage of .34 and a consistency of .76 which indicates that a good proportion of the outcome is covered by the two configurations. Configuration 1 (raw coverage $=.33$, unique coverage $=.11$, consistency $=.77$ ) describes the combination of joint reward systems, management support, multifunctional training and cross-functional teams with the absence of resource dependency. Configuration 2 (raw coverage $=.23$, unique coverage $=.01$, consistency $=.85$ ) describes the presence of cross-functional coordination, management support, multifunctional training and cross-functional teams with the absence of resource dependence. Findings in configuration 2 provide support for Proposition 3, which anticipates that cross-functional coordination combined with other factors leads to marketing adaptiveness.

\subsection{Robustness test using regression analysis}

To supplement the findings from the fsQCA and provide robustness checks, we performed a Tobit regression analysis, treating the configurations obtained by the fsQCA as independent variables and cross-functional coordination and marketing adaptiveness as the dependent variables (Fiss et al., 2013). For comparability with the analysis results from fsQCA, we used fuzzy scores for all variables (Fiss, 2011, Ordanini et al., 2014). Table 5 reports results obtained from two-limit Tobit regression which is considered more appropriate when using fuzzy sets (Fiss et al., 2013). While this robustness test could be informative, it should be treated with caution as results may not be strictly comparable to those of fsQCA analyses. FsQCA uses cases instead of variables to identify configurations of sufficient and necessary conditions for an outcome (Ordanini et al., 2014). As noted by Fiss et al. (2013) we should not treat the findings as competing with those of fsQCA but, 
instead as complementary since they offer additional insights into the phenomenon under investigation.

Table 5: Tobit regression models of configurations

\begin{tabular}{|c|c|c|c|c|c|}
\hline & \multicolumn{3}{|c|}{$\mathrm{DV}=$ Cross-functional coordination } & \multicolumn{2}{|c|}{$\begin{array}{l}\mathrm{DV}=\text { Marketing } \\
\text { adaptiveness }\end{array}$} \\
\hline & Model 1 & Model 2 & Model 3 & Model 4 & Model 5 \\
\hline 1. res*sup*mft*cft & $0.34(0.045) * * *$ & & & & \\
\hline 2. res*reward*sup* ${ }^{*} \sim \mathrm{mft}^{*} \sim \mathrm{cft}$ & & $0.42(.28)$ & & & \\
\hline 3. $\sim \mathrm{res} * \mathrm{reward} * \mathrm{sup}^{*} \sim \mathrm{mft} * \mathrm{cft}$ & & & $-0.48(.26)$ & & \\
\hline 4. res*reward*sup*mft*cft & & & & $0.19(0.014)^{* *}$ & \\
\hline 5. res*sup*mft*cft*cfc & & & & & $0.045(.065)$ \\
\hline Constant & $0.50(.014)^{* * *}$ & $0.66(0.021)^{* * *}$ & $0.94(0.094)^{* * *}$ & $0.50(0.046)$ & $0.60(.04) * * *$ \\
\hline Likelihood-ratio & $54.93 * * *$ & 2.33 & $3.36 *$ & $8.5^{* *}$ & $12.04^{* *}$ \\
\hline Pseudo-R2 & 0.25 & 0.011 & 0.016 & 0.036 & 0.051 \\
\hline
\end{tabular}

As indicated by the regression analysis, only model 1 (representing configuration 1 ) has a significant effect on cross-functional coordination $(b=0.34, p<.001)$. Model 4 (which represents configuration 1 predicting marketing adaptiveness) is found to have a positive significant effect on marketing adaptiveness $(b=0.19, \mathrm{p}<.05)$. The regression analysis partially supports the findings from the fsQCA analysis as models 2, 3 and 5 were not found statistically significant. Findings indicate that configurations with higher raw and unique coverage (models 1 and 4) were supported in the regression analysis.

\section{Discussion and conclusion}

\subsection{Discussion}

Drawing on motivation/ability/opportunity literature and configuration theory (Ketchen et al., 1993, Meyer et al., 1993) the present study incorporates perspectives of different functional units to analyze the different configurational pathways to cross-functional coordination and marketing adaptiveness. It goes beyond the dyadic relationships between marketing and any other different functional units to incorporate perspectives of different functional units as recommended by scholars (e.g., Fisher and Maltz, 1997, Maltz and Kohli, 2000, Song et al., 2000).

Three different configurations emerged to stimulate cross-functional coordination. The three 
configurations explain $81 \%$ of cross-functional coordination (solution coverage $=.81$, solution consistency $=0.88$ ). The existence of multiple sufficient configurations for cross-functional coordination indicates equifinality (Fiss, 2011). This finding provides support for Proposition 1 , which anticipates that disparate configurations are equifinal in leading to cross-functional coordination. Nevertheless, one configuration (configuration1) appears to be the dominant configuration in explaining cross-functional coordination. The other two configurations $(2,3)$ have low scores in raw and unique coverage as they cover a smaller number of cases (six cases). These findings indicate that a configuration combining resource dependency, management support, multifunctional training, and cross-functional teams is the one that has the highest capacity to lead to cross-functional coordination.

The configurations reveal the absence and presence of different causal conditions of crossfunctional coordination. This points to the asymmetric effects of the causal conditions on crossfunctional coordination as posited by Proposition 2 (apart from management support). The results provide evidence that the presence and absence of causal conditions can explain an outcome depending on how these conditions are combined with other causal conditions confirming our second research proposition. The configurations showed that management support can be considered as an almost necessary condition for cross-functional coordination since it is present in all three sufficient configurations. However, the sole presence of management support is not enough to increase cross-functional coordination as other conditions are needed in the causal solutions.

The results in configurations 2 and 3 provide evidence that joint reward systems seems to play a significant role in compensating for the absence of multifunctional training, cross-functional teams (in configuration 2 ) and resource dependency (in configuration 3). This shows that a reward system which encourages employees to aim for broader goals rather than myopically focusing on meeting departmental objectives, will promote coordination across functional units (e.g., Chimhanzi and Morgan, 2005, Griffin and Hauser, 1996).

The configuration solutions for marketing adaptiveness indicate two solutions statements which 
also provide evidence of equifinality. The two sufficient configurations explain $34 \%$ of marketing adaptiveness (solution coverage $=.34$, solution consistency $=0.76$ ). The two solutions show that management support, multifunctional training and cross-functional teams are main ingredients in the causal configurations of marketing adaptiveness. Resource dependency is found to hinder marketing adaptiveness as its absenteeism is highlighted in the two configurations. Cross-functional coordination and joint reward systems appear to play a role in compensating for each other in the configurations leading to marketing adaptiveness. The inclusion of cross-functional coordination in one of the configurations provided evidence for our research Proposition 3. This provides evidence that firms have to maintain a high level of coordination between functional units to be able to adapt quickly to external environment (Kohli and Jaworski, 1990, Krohmer et al., 2002, Narver and Slater, 1990).

\subsection{Implications for theory and research}

In the theoretical realm, our research contributes to literature in several ways. This article is the first to employ configurational theory to explain cross-functional coordination and marketing adaptiveness by using fsQCA to analyze the research propositions. The use of fsQCA and configuration theory captures the complexities underlying cross-functional coordination, a key concept discussed widely in literature but complex to achieve in reality. This study adds to the extant literature on the importance of cross-functional coordination, particularly from an intra-firm perspective, and as a key component of the market orientation construct. It fills a gap in market orientation literature by providing in-depth investigation of how firms can achieve and foster crossfunctional coordination (Kirca et al., 2005). The present study also adds to our understanding of marketing adaptiveness by showing the causal pathways of cross-functional coordination in terms of reconfiguration of specific coordination routines in response to the changing demands from the environment. The findings also contribute to the intra-firm integration literature by helping resolve some of the mixed results regarding the effects of some mechanisms on intra-firm integration and coordination. Prior research reveals positive, neutral and negative effects of variables investigated 
in our research on intra-firm relations. The use of fsQCA enables the discovery of the asymmetric effects of integration mechanisms on achieving coordination, the results of our study demonstrate that the impact of some variables will depend on the other ingredients in the configuration.

\subsection{Implications for practice}

From a managerial perspective, the research findings provide managers with some "recipes" to enhance cross-functional coordination and marketing adaptiveness. As Day (2011) argues, firms can make more sense of volatile and unpredictable markets by developing vigilant market learning capabilities which are fundamentally cross-functional. Failures in coordination may hinder both swift response to changes in the environment and the development of effective strategies to cope with changes (Neill et al., 2007). Therefore, CFC has become a recognized strategy to enable firms to utilize and deploy resources to improve performance (De Luca and Atuahene-Gima, 2007, Hult et al., 2005, Kohli and Jaworski, 1990, Narver and Slater, 1990). By recognizing the relative influence of the different mechanisms of cross-functional coordination, it is possible for managers to utilize them in different ways, particularly in uncertain business environments. Market uncertainty necessitates the gathering and processing of market information to enhance a firm's superior responsiveness (Kohli and Jaworski, 1990). Consequently, compared with firms under stable market conditions, those in uncertain business environments should foster cross-functional relationships to be able to adapt to the environment and remain competitive in the dynamic market (Jeong et al., 2006). Results also show that firms that invest in mechanisms to enhance cross-functional coordination can also enhance marketing adaptiveness (Wind, 2005).For example, our findings suggest that management support, cross-functional teams and multifunctional training are included in the two configurations that yielded a high raw coverage for CFC and marketing adaptiveness. These findings imply that the use of such configurations will enable firms to be more adaptive through the coordination and sharing of information and resources across functional units. On the other hand, our findings also suggest that resource dependency had a negative impact on adaptiveness.

\subsection{Research limitations and future research directions}


As with every research endeavor, this study has several limitations. This study used a self-reported questionnaire and is subsequently susceptible to respondent bias (Phillips, 1981). We acknowledge the limitations of using a cross-sectional survey in testing causal relationships. Therefore, the interpretation of our findings should be considered against the limitation of using data based on retrospective recall from managers which might be unintentionally biased (March and Sutton, 1997). Although we used multiple informants in each firm to control for the potential bias of the single management informant (Podsakoff et al., 2003), managers' cognitive biases, particularly when the measurements are related to performance information, remain problematic when we come to interpreting results (March and Sutton, 1997, Rong and Wilkinson, 2011). Another limitation in this research is that the measures used to assess the research constructs were all perceptual and some of our measurement scales exhibited low reliability, thereby necessitating the deletion of some items. The relatively low reliabilities found with a few measures suggests that caution should be used in the interpretation of results. Finally, despite the advantages of using fsQCA in identifying the best configurations for a desired outcome, it also carries some limitations. FsQCA, unlike regression analysis, cannot conclude on the unique contribution of each independent variable to the desired outcome (Vis, 2012) Furthermore, the causal predictors should be selected with care and based on sound research as they limit the explanation of the outcome. Finally, the analysis results are very sensitive to the calibration of the data which are based on the researcher's decisions.

An important avenue for future research arises from the limitation imposed by the descriptive, cross-sectional research design employed. Future research could adopt a longitudinal perspective to allow for the examination of the influence of changing contingencies on the use of different mechanisms to enhance cross-functional coordination and marketing adaptiveness over time. As suggested in this research, the MAO theory provided a promising theoretical framework. An important research direction will be to consider the MAO dimensions as latent constructs and develop measurement scales for them. Conducting such research will have a significant impact on the literature as it will allow for the testing of relationships between organizational factors as 
antecedents for coordination and their relationships with the latent constructs' motivation to coordinate, ability to coordinate, and opportunity to coordinate.

\subsection{Conclusion}

The main argument of this research is that coordination is a desired behavior which firms seek to foster in order to be able to adapt to the ever-changing market environment. The study identified causal configurations to enhance cross-functional coordination and examined their implications for marketing adaptiveness. The analysis demonstrates that fsQCA provides a unique method to examine the different pathways leading to cross-functional coordination and marketing adaptiveness. Management support for coordination is found to be the almost-necessary condition for achieving the desired outcomes in the Egyptian context as it is present in all configurations. 


\begin{tabular}{l}
\hline Construct and reference \\
\hline \\
Resource Dependency \\
$(\alpha=0.88 ; \mathrm{CR}=0.92 ; \mathrm{AVE}=0.85)$ \\
(Ruekert and Walker, 1987b)
\end{tabular}

Joint Reward System

$(\alpha=0.77 ; \mathrm{CR}=0.83 ; \mathrm{AVE}=0.64)$

(Song et al., 1997)

Top management support $(\alpha=\mathrm{NA} ; \mathrm{CR}=\mathrm{NA} ; \mathrm{AVE}=\mathrm{NA})$ (Song et al., 1997)

Multifunctional Training $(\alpha=0.71 ; \mathrm{CR}=0.73 ; \mathrm{AVE}=0.54)$ (Maltz and Kohli, 2000)

Cross-Functional Team Use: $(\alpha=0.77 ; \mathrm{CR}=0.90 ; \mathrm{AVE}=0.63)$ (Maltz and Kohli, 2000)

Cross functional coordination** $(\alpha=0.883 ; \mathrm{CR}=0.73 ; \mathrm{AVE}=0.52)$

Harmony of cross-functional relationships

$(\alpha=0.67 ; \mathrm{CR}=0.71 ; \mathrm{AVE}=0.52)$

(Song et al., 2000)

Quality of cross-functional information

$(\alpha=\mathrm{NA} ; \mathrm{CR}=\mathrm{NA} ; \mathrm{AVE}=\mathrm{NA})$

(Song et al., 2000)

Level of cross-functional involvement

$(\alpha=0.92 ; \mathrm{CR}=0.92 ; \mathrm{AVE}=0.75)$

(Song et al., 2000)

Adaptiveness

$(\alpha=0.79 ; \mathrm{CR}=0.82 ; \mathrm{AVE}=0.83)$

(Ruekert et al., 1985)
Item

ing

For your department to accomplish its goals and responsibilities, how much does it need the services, resources, or support from the marketing department?

For the marketing unit to accomplish its goals and responsibilities, how much does it need the services, resources, or support from your department?

The marketing and other functions share equally in the rewards from a well implemented market strategy.

Senior management promotes firm loyalty over departmental loyalty.*

Managers' evaluations are based on joint performance with other managers.

Your overall compensation depends on your contribution to other functional units.

Our organizational structure facilitates cross-functionalcoordination.*

Our management formally promotes and encourages cross-functional coordination.

Our management provides opportunities for functional units to socialize together.*

Managers participate in training programs that acquaint us with areas outside our specific function.

Experience in more than one functional area is a consideration for promotion and advancement.

We receive training in how to communicate with people in other functional areas.

Managers are trained to do more than one job.*

We participate in training sessions with managers from other functional areas.

Our firm uses teams that include mid-level managers from multiple functions to:

Visit external customers.

Develop new products/ services.

Develop product performance goals

Develop SBU-level financial goals.

Identify new markets or customers.

Review the performance of the firm.

Review the performance of a product or product line.

Overall, we are satisfied with the relationship between our department and other functional units*.

All functional units try their best to carry out the responsibilities and commitments made to each other.

There is a give-and-take relationship among the functional units.

There is open communication among the functional units.*

The information presented by one department to the others is accurate.

In general, information from other functional units lacks credibility with this department. (Reversed code).*

Our cross-functional communications are often timely.

Our department is involved in test marketing/trial selling prior to launch. $\quad .934$

Our department is involved in determining desired product features $\quad .906$

Adapting your marketing strategy adequately to changes in the business environment $\quad .913$ of your business unit.

Adapting your marketing strategy adequately to changes in competitors' marketing strategies. 9

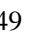

(1)
.

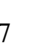

\section{4} 695

\section{.059}


ARNDT, A. D., KARANDE, K. \& LANDRY, T. D. 2011. An Examination of Frontline Crossfunctional Integration during Retail Transactions. Journal of Retailing, 87, 225-241.

ARNETT, D. B. \& WITTMANN, C. M. 2014. Improving marketing success: The role of tacit knowledge exchange between sales and marketing. Journal of Business Research, 67, 324331.

ATUAHENE-GIMA, K. 1996. Market Orientation and Innovation. Journal of Business Research, 35, 93-103.

ATUAHENE-GIMA, K. 2005. Resolving the Capability-Rigidity Paradox in New Product Innovation. Journal of Marketing, 69, 61-83.

AYERS, D., DAHLSTROM, R. \& SKINNER, S. J. 1997. An Exploratory Investigation of Organizational Antecedents to New Product Success. Journal of Marketing Research (JMR), 34, 107-116.

BAUER, J., SCHMITT, P., MORWITZ, V. \& WINER, R. 2013. Managerial decision making in customer management: adaptive, fast and frugal? Journal of the Academy of Marketing Science, 41, 436-455.

BEER, M., SPECTOR, B., LAWRENCE, P. R. \& MILLS, D. Q. 1988. Managing Human Assets, Macmillan Publishers.

BERGKVIST, L. \& ROSSITER, J. R. 2007. The Predictive Validity of Multiple-Item Versus Single-Item Measures of the Same Constructs. Journal of Marketing Research (JMR), 44, 175-184.

BROWN, S. L. \& EISENHARDT, K. M. 1995. Product Development: Past Research, Present Findings, And Future Directions. Academy of Management Review, 20, 343-378.

CALANTONE, R. \& RUBERA, G. 2012. When Should RD\& E and Marketing Collaborate? The Moderating Role of Exploration-Exploitation and Environmental Uncertainty. Journal of Product Innovation Management, 29, 144-157.

CHIMHANZI, J. \& MORGAN, R. E. 2005. Explanations from the marketing/human resources dyad for marketing strategy implementation effectiveness in service firms. Journal of Business Research, 58, 787-796.

CHURCHILL, G. A. 1979. A Paradigm For Developing Better Measures Of Marketing Constructs. Journal of Marketing Research 16, 64-73.

CLARK, B. H., ABELA, A. V. \& AMBLER, T. 2005. Organizational motivation, opportunity and ability to measure marketing performance. Journal of Strategic Marketing, 13, 241-259.

CUIJPERS, M., GUENTER, H. \& HUSSINGER, K. 2011. Costs and benefits of inter-departmental innovation collaboration. Research Policy, 40, 565-575.

DAY, G. S. 2011. Closing the Marketing Capabilities Gap. Journal of Marketing, 75, 183-195.

DE LUCA, L. M. \& ATUAHENE-GIMA, K. 2007. Market Knowledge Dimensions and CrossFunctional Collaboration: Examining the Different Routes to Product Innovation Performance. Journal of Marketing, 71, 95-112.

EISENHARDT, K. M. \& MARTIN, J. A. 2000. Dynamic Capabilities: What Are They? Strategic Management Journal, 21, 1105.

ENZ, M. G. \& LAMBERT, D. M. 2012. Using cross-functional, cross-firm teams to co-create value: The role of financial measures. Industrial Marketing Management, 41, 495-507.

EPPLER, M. J. \& MENGIS, J. 2004. The Concept of Information Overload: A Review of Literature from Organization Science, Accounting, Marketing, MIS, and Related Disciplines.

ERNST, H., HOYER, W. D. \& RÜBSAAMEN, C. 2010. Sales, Marketing, and Research-andDevelopment Cooperation Across New Product Development Stages: Implications for Success. Journal of Marketing, 74, 80-92.

FISHER, R. J. \& MALTZ, E. 1997. Enhancing Communication Between Marketing and Engineering: The Moderating Role of Relative Functional Identification. Journal of Marketing, 61, 54-70. 
FISS, P., SHARAPOV, D. \& CRONQVIST, L. 2013. Opposites attract? Opportunities and challenges for integrating large-N QCA and econometric analysis. Political Research Quarterly, 66, 191-197.

FISS, P. C. 2007. A set-theoretic approach to organizational configurations. Academy of Management Review, 32, 1180-1198.

FISS, P. C. 2011. Building better casual theories: A fuzzy set approach to typologies in organizational research. Academy of Management Journal, 54, 393-420.

GALBRAITH, J. 1994. Competing with Flexible Lateral Organizations, Reading, MA, AddisonWesley.

GALBRAITH, J. R. 1973. Designing complex organizations, Reading, MA7 Addison-Wesley.

GANTER, A. \& HECKER, A. 2014. Configurational paths to organizational innovation: qualitative comparative analyses of antecedents and contingencies. Journal of Business Research, 67, 1285-1292.

GOOD, D. J. \& SCHULTZ, R. J. 1997. Technological Teaming as a Marketing Strategy. Industrial Marketing Management, 26, 413-422.

GRECKHAMER, T., MISANGYI, V. F., ELMS, H. \& LACEY, R. 2008. Using Qualitative Comparative Analysis in Strategic Management Research: An Examination of Combinations of Industry, Corporate, and Business-Unit Effects. Organizational Research Methods, 11, 695-726.

GRIFFIN, A. \& HAUSER, J. R. 1996. Integrating R\&D and Marketing: A Review and Analysis of the Literature. Journal of Product Innovation Management, 13, 191-215.

GUPTA, A. K., RAJ, S. P. \& WILEMON, D. 1986. A Model for Studying R\&D--Marketing Interface in the Product Innovation Process. Journal of Marketing, 50, 7-17.

GUPTA, A. K. \& WILEMON, D. 1991. Improving R\&D/Marketing Relations in Technology Based Companies: Marketing's Perspective. Journal of Marketing Management, 7, 25-45.

HIRUNYAWIPADA, T., BEYERLEIN, M. \& BLANKSON, C. 2010. Cross-functional integration as a knowledge transformation mechanism: Implications for new product development. Industrial Marketing Management, 39, 650-660.

HOLLAND, S., GASTON, K. \& GOMES, J. 2000. Critical success factors for cross-functional teamwork in new product development. International Journal of Management, 2, 231-259.

HULT, G. T. M., JR, D. J. K. \& SLATER, S. F. 2005. Market Orientation and Performance: An Integration of Disparate Approaches. Strategic Management Journal, 26, 1173-1181.

HUTT, M. D. 1995. Cross-Functional Working Relationships in Marketing. Journal of the Academy of Marketing Science, 23, 351-357.

JANSEN, J. J. P., TEMPELAAR, M. P., VAN DEN BOSCH, F. A. J. \& VOLBERDA, H. W. 2009. Structural Differentiation and Ambidexterity: The Mediating Role of Integration Mechanisms. Organization Science, 20, 797-811.

JAWORSKI, B. J. \& KOHLI, A. K. 1993. Market orientation: Antecedents and consequences. Journal of Marketing, 57, 53.

JEONG, I., PAE, J. H. \& ZHOU, D. 2006. Antecedents and consequences of the strategic orientations in new product development: The case of Chinese manufacturers. Industrial Marketing Management, 35, 348-358.

KAHN, K. B. \& MENTZER, J. T. 1998. Marketing's Integration with Other Departments. Journal of Business Research, 42, 53-62.

KETCHEN, J. D. J., THOMAS, J. B. \& SNOW, C. C. 1993. ORGANIZATIONAL CONFIGURATIONS AND PERFORMANCE: A COMPARISON OF THEORETICAL APPROACHES. Academy of Management Journal, 36, 1278-1313.

KIRCA, A. H., JAYACHANDRAN, S. \& BEARDEN, W. O. 2005. Market Orientation: A MetaAnalytic Review and Assessment of Its Antecedents and Impact on Performance. Journal of Marketing, 69, 24-41.

KLINGBERG, T. 2009. The overflowing brain: information overload and the limits of working memory, New York, Oxford University Press.

KOHLI, A. K. \& JAWORSKI, B. J. 1990. Market Orientation: The Construct, Research Propositions, and Managerial Implications. Journal of Marketing, 54, 1-18.

KROHMER, H., HOMBURG, C. \& WORKMAN, J. P. 2002. Should marketing be cross-functional? 
Conceptual development and international empirical evidence. Journal of Business Research, 55, 451-465.

KUEN-HUNG, T., CHI-TSUN, H. \& MU-LIN, T. 2013. Reviews of market drivers of new product performance. International Journal of Market Research, 55, 719-738.

LADLEY, D., WILKINSON, I. \& YOUNG, L. 2015. The impact of individual versus group rewards on work group performance and cooperation: A computational social science approach. Journal of Business Research, 68, 2412-2425.

LAWRENCE, P. R. \& LORSCH, J. W. 1967. Differentiation and Integration in Complex Organizations. Administrative Science Quarterly, 12, 1-47.

LE MEUNIER-FITZHUGH, K., MASSEY, G. R. \& PIERCY, N. F. 2011. The impact of aligned rewards and senior manager attitudes on conflict and collaboration between sales and marketing. Industrial Marketing Management, 40, 1161-1171.

LEE, K. B. \& WONG, V. 2012. Organizational coordination, development proficiency, and on-time completion of development and international rollout: A contingency analysis of external environments. Journal of Business Research, 65, 389-401.

LEISCHNIG, A. \& KASPER-BRAUER, K. 2015. Employee Adaptive Behavior in Service Enactments. Journal of Business Research, 68, 273-280.

MACLNNIS, D. J., MOORMAN, C. \& JAWORSKI, B. J. 1991. Enhancing and Measuring Consumers' Motivation, Opportunity, and Ability to Process Brand Information from Ads. Journal of Marketing, 55, 32-53.

MALTZ, E. \& KOHLI, A. K. 2000. Reducing Marketing's Conflict With Other Functions: The Differential Effects of Integrating Mechanisms. Journal of the Academy of Marketing Science, 28, 479.

MALTZ, E., SOUDER, W. E. \& KUMAR, A. 2001. Influencing R\&D/marketing integration and the use of market information by R;D managers: intended and unintended effects of managerial actions. Journal of Business Research, 52, 69-82.

MARCH, J. G. \& SUTTON, R. I. 1997. Crossroads-Organizational Performance as a Dependent Variable. Organization Science, 8, 698-706.

MEUER, J. 2014. Archetypes of Inter-firm Relations in the Implementation of Management Innovation: A Set-theoretic Study in China's Biopharmaceutical Industry. Organization Studies (01708406), 35, 121-145.

MEYER, A. D., TSUI, A. S. \& HININGS, C. R. 1993. Configurational Approaches to Organizational Analysis. Academy of Management Journal, 36, 1175-1195.

MILES, M. B. \& HUBERMAN, A. M. 1994. Qualitative Data Analysis: An Expanded Sourcebook, London, Sage.

MINTZBERG, H., JORGENSEN, J., DOUGHERTY, D. \& WESTLEY, F. 1996. Some Surprising Things About Collaboration--Knowing How People Connect Makes It Work Better. Organizational Dynamics, 25, 60-71.

MOENAERT, R. K. \& SOUDER, W. E. 1990. An Information Transfer Model for Integrating Marketing and R\&D Personnel in New Product Development Projects. Journal of Product Innovation Management, 7, 91-107.

NAKATA, C. \& IM, S. 2010. Spurring Cross-Functional Integration for Higher New Product Performance: A Group Effectiveness Perspective. Journal of Product Innovation Management, 27, 554-571.

NARVER, J. C. \& SLATER, S. F. 1990. The effect of a market orientation on business profitability. Journal of Marketing, 54, 20-35.

NEILL, S., MCKEE, D. \& ROSE, G. M. 2007. Developing the organization's sensemaking capability: Precursor to an adaptive strategic marketing response. Industrial Marketing Management, 36, 731-744.

OLSON, E. M., WALKER, J. O. C. \& RUEKERT, R. W. 1995. Organizing for effective new product development: The moderating role of product innovativeness. Journal of Marketing, $59,48$.

ORDANINI, A. \& MAGLIO, P. P. 2009. Market Orientation, Internal Process, and External Network: A Qualitative Comparative Analysis of Key Decisional Alternatives in the New Service Development. Decision Sciences, 40, 601-625. 
ORDANINI, A., PARASURAMAN, A. \& RUBERA, G. 2014. When the Recipe Is More Important Than the Ingredients: A Qualitative Comparative Analysis (QCA) of Service Innovation Configurations. Journal of Service Research, 17, 134-149.

PARRY, M. E. \& SONG, X. M. 1993. Determinants of R\&D--Marketing Integration in High-Tech Japanese Firms. Journal of Product Innovation Management, 10, 4-22.

PFEFFER, J. \& SALANCIK, G. R. 1978. The External Control of Organizations: A Resource Dependence Perspective, New York, Harper \& Row.

PHILLIPS, L. W. 1981. Assessing measurement error in key informant reports: A methodological note on organizational analysis in marketing. Journal of Marketing Research (JMR), 18, $395-415$.

PINTO, M. B., PINTO, J. K. \& PRESCOTT, J. E. 1993. Antecedents and Consequences of Project Team Cross-functional Cooperation. Management Science, 39, 1281-1297.

PODSAKOFF, P. M., MACKENZIE, S. B., JEONG-YEON, L. \& PODSAKOFF, N. P. 2003. Common Method Biases in Behavioral Research: A Critical Review of the Literature and Recommended Remedies. Journal of Applied Psychology, 88, 879.

PODSAKOFF, P. M. \& ORGAN, D. W. 1986. Self-Reports in Organizational Research: Problems and Prospects. Journal of Management, 12, 531-544.

RAGIN, C. \& SONNETT, J. 2005. Between Complexity and Parsimony: Limited Diversity, Counterfactual Cases, and Comparative Analysis. In: KROPP, S. \& MINKENBERG, M. (eds.) Vergleichen in der Politikwissenschaft. VS Verlag für Sozialwissenschaften.

RAGIN, C. C. 2000. Fuzzy-set social science, Chicago, The University of Chicago Press.

RAGIN, C. C. 2008. Redesigning social inquiry: Fuzzy sets and beyond, Chicago, University of Chicago Press.

RINDOVA, V. P. \& KOTHA, S. 2001. CONTINUOUS "MORPHING": COMPETING THROUGH DYNAMIC CAPABILITIES, FORM, AND FUNCTION. Academy of Management Journal, 44, 1263-1280.

RONG, B. \& WILKINSON, I. F. 2011. What do managers' survey responses mean and what affects them? The case of market orientation and firm performance. Australasian Marketing Journal (AMJ), 19, 137-147.

RUEKERT, R. W. 1992. Developing a market orientation: An organizational strategy perspective. International Journal of Research in Marketing, 9, 225-245.

RUEKERT, R. W. \& WALKER, J. O. C. 1987a. Interactions Between Marketing And R\&D Departments In Implementing Different Business Strategies. Strategic Management Journal, 8, 233-248.

RUEKERT, R. W. \& WALKER, J. O. C. 1987b. Marketing's Interaction with Other Functional Units: A Conceptual Framework and Empirical Evidence. Journal of Marketing, 51, 1-19.

RUEKERT, R. W., WALKER JR, O. C. \& ROERING, K. J. 1985. The Organization of Marketing Activities: A Contingency Theory of Structure and Performance. Journal of Marketing, 49, 13-25.

SANCHEZ, R. 1995. Strategic flexibility in product competition. Strategic Management Journal, $16,135-159$.

SIEMSEN, E., ROTH, A. V. \& BALASUBRAMANIAN, S. 2008. How motivation, opportunity, and ability drive knowledge sharing: The constraining-factor model. Journal of Operations Management, 26, 426-445.

SKARMEAS, D., LEONIDOU, C. N. \& SARIDAKIS, C. 2014. Examining the role of CSR skepticism using fuzzy-set qualitative comparative analysis. Journal of Business Research, 67, 1796-1805.

SLATER, S. F. \& NARVER, J. C. 1995. Market orientation and the learning organization. Journal of Marketing, 59, 63.

SONG, M. \& SWINK, M. 2009. Marketing-Manufacturing Integration Across Stages of New Product Development: Effects on the Success of High- and Low-Innovativeness Products. IEEE Transactions on Engineering Management, 56, 31-44.

SONG, M. \& XIE, J. 2000. Does Innovativeness Moderate the Relationship Between CrossFunctional Integration and Product Performance? Journal of International Marketing, 8, 6189. 
SONG, X. M., MONTOYA-WEISS, M. M. \& SCHMIDT, J. B. 1997. Antecedents and Consequences of Cross-Functional Cooperation: A Comparison of R\&D, Manufacturing, and Marketing Perspectives. Journal of Product Innovation Management, 14, 35-47.

SONG, X. M., XIE, J. \& DYER, B. 2000. Antecedents and Consequences of Marketing Managers' Conflict-Handling Behaviors. Journal of Marketing, 64, 50-66.

TANG, T., FANG, E. \& FENG, W. 2014. Is Neutral Really Neutral? The Effects of Neutral UserGenerated Content on Product Sales. Journal of Marketing, 78, 41-58.

TROY, L. C., HIRUNYAWIPADA, T. \& PASWAN, A. K. 2008. Cross-Functional Integration and New Product Success: An Empirical Investigation of the Findings. Journal of Marketing, 72, 132-146.

TSAI, K.-H. \& HSU, T. T. 2014. Cross-Functional collaboration, competitive intensity, knowledge integration mechanisms, and new product performance: A mediated moderation model. Industrial Marketing Management, 43, 293-303.

VAKRATSAS, D. \& MA, Z. 2009. Firm adaptiveness and performance heterogeneity: the case of sales-advertising dynamics in an evolving product market. Journal of Evolutionary Economics, 19, 21-40.

VIS, B. 2012. The Comparative Advantages of fsQCA and Regression Analysis for Moderately Large-N Analyses. Sociological Methods \& Research, 41, 168-198.

WALL, S. \& LEPSINGER, R. 1994. Cross-functional obstacles. Training, May, 125-126.

WANG, C. L. \& AHMED, P. K. 2007. Dynamic capabilities: A review and research agenda. International Journal of Management Reviews, 9, 31-51.

WEITZ, B. A., SUJAN, H. \& SUJAN, M. 1986. Knowledge, Motivation, and Adaptive Behavior: A Framework for Improving Selling Effectiveness. Journal of Marketing, 50, 174-191.

WIND, Y. 2005. Marketing as an engine of business growth: a cross-functional perspective. Journal of Business Research, 58, 863-873.

WOICESHYN, J. \& DAELLENBACH, U. 2005. Integrative capability and technology adoption: evidence from oil firms. Industrial \& Corporate Change, 14, 307-342.

WOODSIDE, A. G. 2013. Moving beyond multiple regression analysis to algorithms: Calling for adoption of a paradigm shift from symmetric to asymmetric thinking in data analysis and crafting theory. Journal of Business Research, 66, 463-472.

WOODSIDE, A. G., HSU, S.-Y. \& MARSHALL, R. 2011. General theory of cultures' consequences on international tourism behavior. Journal of Business Research, 64, 785-799.

WOODSIDE, A. G., PRENTICE, C. \& LARSEN, A. 2015. Revisiting Problem Gamblers' Harsh Gaze on Casino Services: Applying Complexity Theory to Identify Exceptional Customers. Psychology \& Marketing, 32, 65-77.

WU, P.-L., YEH, S.-S., HUAN, T.-C. \& WOODSIDE, A. G. 2014. Applying complexity theory to deepen service dominant logic: Configural analysis of customer experience-and-outcome assessments of professional services for personal transformations. Journal of Business Research, 67, 1647-1670.

ZOLLO, M. \& WINTER, S. G. 2002. Deliberate Learning and the Evolution of Dynamic Capabilities. Organization Science, 13, 339-351.

ZOTT, C. 2003. DYNAMIC CAPABILITIES AND THE EMERGENCE OF INTRAINDUSTRY DIFFERENTIAL FIRM PERFORMANCE: INSIGHTS FROM A SIMULATION STUDY. Strategic Management Journal, 24, 97. 